\begin{tabular}{|c|c|c|c|c|c|c|}
\hline \multirow{4}{*}{ Impact Factor: } & ISRA (India) & $=3.117$ & SIS (USA) & $=0.912$ & ICV (Poland) & $=6.630$ \\
\hline & ISI (Dubai, UAE & $=0.829$ & РИНЦ (Russia & $=0.156$ & PIF (India) & $=1.940$ \\
\hline & GIF (Australia) & $=0.564$ & ESJI (KZ) & $=8.716$ & IBI (India) & $=4.260$ \\
\hline & JIF & $=1.500$ & SJIF (Morocco & $=5.667$ & OAJI (USA) & $=0.350$ \\
\hline
\end{tabular}

\begin{tabular}{|c|c|}
\hline $\begin{array}{l}\text { SOI: } \frac{1.1 / \mathrm{TA}}{\mathrm{Sc}} \\
\text { International Sc } \\
\text { Theoretical \& A }\end{array}$ & $\begin{array}{l}S \text { DOI: } 10.15863 / T A S \\
\text { ientific Journal } \\
\text { pplied Science }\end{array}$ \\
\hline p-ISSN: 2308-4944 (print) & e-ISSN: 2409-0085 (online) \\
\hline Year: 2019 Issue: 05 & Volume: 73 \\
\hline Published: 30.05 .2019 & http://T-Science.org \\
\hline
\end{tabular}

SECTION 31. Jurisprudence. UDC 34.037
QR - Issue
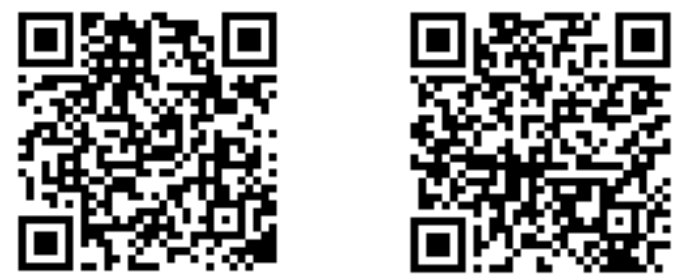

Irina Leonidovna Vishnevskaya Subject image of forensic examination, IP.Pravovaya information and services,

Russia,

Vishnevskaya4@gmail.com

\title{
SUBJECT IMAGE OF FORENSIC EXAMINATION
}

Abstract: The foundations of the methodology, which is a criterion for constructing the dialectical structure of thinking in philosophy and psychology involved in the process of cognition, are considered, which is a fundamental factor in the subject-matter image of forensic expertise.

Key words: subject, forensic expert activity, evidence in legal proceedings, judicial opinions, formal logic, dialectical logic, analysis, synthesis.

Language: Russian

Citation: Vishnevskaya, I. L. (2019). Subject image of forensic examination. ISJ Theoretical \& Applied Science, 05 (73), 579-582.

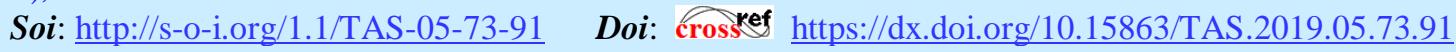

\section{СУБЪЕКТНЫЙ ОБРАЗ СУДЕБНОЙ ЭКСПЕРТИЗЫ}

Аннотация: Рассмотрены основы методологии, являющейся критерием построения диалектической структуры мышиения в философии и психологии, участвующей в процессе познания, что является основополагаюшци фактором субъектного образа судебно-экспертной деятельности.

Ключевые слова: субъект, судебно-экспертная деятельность, доказательства в судопроизводстве, судебные заключения, формальная логика, диалектическая логика, анализ, синтез.

\section{Introduction}

Судебной экспертизой представлена деятельность, определяющая конечным результатом установленных доказательств, применяемых в судопроизводстве, обусловленных требованиями статей УПК РФ, ГПК РФ, АПК РФ.

Судебная экспертиза - процессуальное действие, состоящее из проведения исследований и дачи заключения субъектным экспертом по вопросам, разрешение которых требует специальных знаний в области науки, техники, искусства или ремесла и которые поставлены перед экспертом судом, судьей, органом дознания, лицом, производящим дознание, следователем, в целях установления обстоятельств, подлежащих доказыванию по конкретному делу. Судебноэкспертное исследование по своей гносеологической сущности является разновидностью процесса познания объективной действительности, осуществляемого путем применения методов различных наук на основе познания мира человеком, структуры познавательной деятельности, форм знания в его отношении к действительности, критериев истинности и достоверности знания, его природы и границ.

\section{Materials and Methods}

Осуществляемая судебно-экспертная деятельность отражает специфику экспертных исследований специалиста, в порядке статей, изложенных в Федеральном законе № 73 - Ф3 от 31.05.2001г. [7, с. 8].

Научный фундамент, образованный систематической судебной практикой на основе эмпирического материала экспертных задач, методов и приемов исследования, позволяет сформировать начало отдельных родов судебных экспертиз и частных теорий.

Научные методы и средства, используемые в деятельности судебных экспертов и экспертных учреждений, происходят не для открытия новых законов и закономерностей природы и общества 


\begin{tabular}{llllll} 
& ISRA (India) $=\mathbf{3 . 1 1 7}$ & SIS (USA) & $=\mathbf{0 . 9 1 2}$ & ICV (Poland) & $=\mathbf{6 . 6 3 0}$ \\
Impact Factor: & ISI (Dubai, UAE) $=\mathbf{0 . 8 2 9}$ & PUHL (Russia) $=\mathbf{0 . 1 5 6}$ & PIF (India) & $=\mathbf{1 . 9 4 0}$ \\
& GIF (Australia) $=\mathbf{0 . 5 6 4}$ & ESJI (KZ) & $=\mathbf{8 . 7 1 6}$ & IBI (India) & $=\mathbf{4 . 2 6 0}$ \\
& JIF & $\mathbf{1 . 5 0 0}$ & SJIF (Morocco) $=\mathbf{5 . 6 6 7}$ & OAJI (USA) & $\mathbf{0 . 3 5 0}$ \\
\hline
\end{tabular}

или для установления научных фактов, теорий и проверки научных гипотез, а для решения практических задач по установлению истины, путем представленных доказательств в экспертном заключении процесса гражданского или уголовного производства [1, с.74].

Таким образом, в практической судебноэкспертной деятельности применяются те же методы, что и в научном исследовании, если их использование не противоречит требованиям законности и этическим нормам и отвечает принципу допустимости в его общей форме. В остальных случаях судебный эксперт практически не ограничивается в выборе средств и методов исследования, при условии соблюдения общих правил работы с доказательствами.

По совокупности доказательств, представленных в заключении, в соответствии с ГПК, АПК, УПК, эксперт должен поставить свою подпись, удостоверяющую, что он предупрежден об ответственности по ст. 307 УК РФ за дачу заведомо ложного заключения., иллюстративные материалы, полученные в результате применения экспертных методов оформляются, как приложения к судебному заключению.

Необходимо отметить, что в судебноэкспертной деятельности базовым методом исследования является диалектический метод познания.

Законы материалистической диалектики имеют всеобщее значение и присущи любой форме движения материи: развитию природы, общества, мышления.

Руководствуясь понятием и сущностью специальных профессиональных знаний эксперта, необходимых в судебно-экспертных исследованиях, основополагающим фактором также являются его субъективные суждения, основанные на имеющихся фактах, методиках, теориях, подзаконных актах, являющиеся конечным результатом квалифицированного мнения и выводов, положенных в основу решения суда, постановления, приговора [2, с.93].

Всеобщий диалектический метод объединяет наиболее фундаментальные принципы и приемы, регулирующие всякую познавательную и практическую деятельность. Методология научных исследований базируется на диалектическом подходе к материальной действительности. При этом основная роль принадлежит диалектике о способности материи к отражению, о взаимосвязи и взаимообусловленности явлений, о соотношении единичного, особенного и общего, например, в процессе экспертного исследования возможен анализ самых разных форм отражения: начиная от простейших, связанных с контактным взаимодействием двух объектов, и до значительно более сложных, когда факты и обстоятельства позволяют проследить причинно-следственные связи и установить механизм события по его отображениям. Систематически возникающие не ясности в деянии причинно-следственной связи тех, или иных событий, приводят к необходимости привлечения экспертов, к судопроизводству, обладающих специальными познаниями в той или иной области науки, ремесла, для установления истины [5, с.28].

Изучая новые типы причинных связей, образовалось взаимодействие, как наиболее сложный тип связи с обратным воздействием, то есть, влиянием друг на друга, с одновременной ролью причины и следствия [11, с.81].

В процессе изучения направленности субъектного образа судебной экспертизы, проведены параллели действий познавательной и исследовательской деятельности.

Познание, являясь основным предметом науки гносеологии, выступает не только процессом накопления знаний, мысленной обработки полученной информации для формирования правильного представления об определенных объектах, но и несет в себе систему деятельности, обеспечивающую развитие самого процесса познания [3, с.115].

При анализе уже имеющегося опыта и возникновении сомнений, строится гипотеза, требующая дополнительной проверки результатов исследований, следовательно, возникновение противоречащих факторов (исходных, расчетных, нормативных) приводит также к формированию экспертного убеждения.

По итогам мыслительной деятельности, выражающейся в логических операциях, которые способствуют выявлению необходимых закономерностей, признаков, свойств, особенностей объекта исследования, происходит реализация предшествующих этапов познавательной деятельности. В дальнейшем, по результатам исследований и сформированного убеждения эксперта, в виде оценочного суждения об объекте экспертного исследования, умозаключения, возникает субъектный образ судебного заключения, в виде конечного результата объективных выводов на поставленные вопросы. Результаты исследований природы и процесса формирования внутреннего убеждения эксперта обусловлены психологической структурой судебно-экспертной деятельности [9, $\mathrm{c}, 35]$. 


\begin{tabular}{llllll} 
& ISRA (India) $=\mathbf{3 . 1 1 7}$ & SIS (USA) & $=\mathbf{0 . 9 1 2}$ & ICV (Poland) & $=\mathbf{6 . 6 3 0}$ \\
Impact Factor: & ISI (Dubai, UAE) $=\mathbf{0 . 8 2 9}$ & PUHL (Russia) $=\mathbf{0 . 1 5 6}$ & PIF (India) & $=\mathbf{1 . 9 4 0}$ \\
& GIF (Australia) $=\mathbf{0 . 5 6 4}$ & ESJI (KZ) & $=\mathbf{8 . 7 1 6}$ & IBI (India) & $=\mathbf{4 . 2 6 0}$ \\
& JIF & $\mathbf{1 . 5 0 0}$ & SJIF (Morocco) $=\mathbf{5 . 6 6 7}$ & OAJI (USA) & $\mathbf{0 . 3 5 0}$ \\
\hline
\end{tabular}

Правильно сформулированные задачи экспертизы, предоставленные в распоряжение эксперта исходные данные: документы, законодательные акты, информационные базы, сравнительные образцы - способствуют реальным условиям для качественного проведения экспертизы, решению поставленных вопросов, и правильного выбора необходимых методик.

Сформулированные основные требования к эксперту, в исполнение статей Федерального закона «об экспертной деятельности, статьи 7,8», это незаинтересованность в исходе дела, объективность мнений и суждений, возможность проявления инициативы при проведении исследования, в целях обнаружения объективных признаков, которые в делопроизводстве, проверяемые и оцениваемые судом могут привести к истине. Оценка заключений экспертов, в соответствии с требованиями статей $84,85,86$ ГПК РФ проверяется и оценивается судом, следственными органами [7, с.115].

Определяя субъектные качества специалиста, основным из которых, в статусе эксперта, является специфика познавательного труда, методология экспертных исследований, понимание общей концепции направления экспертного заключения с системой знаний свойств, законов и закономерностей изучаемого объекта [10, с.55].

Процесс экспертной деятельности способствует возникновению новых знаний, разработок, как пути к методам высокой степени научной обоснованности судебных заключений. Субъектные качества эксперта, как и специальные знания, полученные и ограниченные профессиональным образованием, обеспечиваются высокими требованиями и закрепляются в процессе подготовки по конкретной экспертной специальности.

Диалектический метод, выражая общие методологические принципы процесса познания позволяет сконструировать систему частных методов, пронизывающих и входящих в их содержание в качестве основополагающего элемента.

Диалектические структуры мышления в философии и психологии, в свою очередь, в процессе познания, предполагают определенные действия, связанные с дифференцированием единого целого (объект исследования), с последующим анализом его составляющих [8, с.47].

В пути экспертного познания, происходящий синтез какой-либо материи или сущности, определяет возможности логического мышления в категории формальной логики, определяющей понятия анализа, синтеза, индукции, дедукции, гипотезы, аналогии и не только, все это уже не связано с конкретным предметом исследования, а связано с мыслительным процессом обработки имеющихся фактов. Из соблюдаемых требований формальной логики и ее эффективного действия и следует превосходство диалектической логики, как всеобщей методологии, являющейся базовой [12, c.28].

Включая изложенные категории в круг понятий психологии, с образованием и моделированием аппарата мышления, в итоге создается субъективный образ судебной экспертизы, в числе других аспектов познания, позволяемых субъекту складывать противоречия и постигать тождество противоположностей в классических исследованиях психологии [4, с.47].

Все эти категории, в сравнении с методами исследований, относятся к ступеням более высокого порядка, являющимися важной составляющей интеллектуальных субъективных возможностей, определяющих статус эксперта.

Признание причинности и закономерности явлений основано на материалистическом понимании научного познания мира. Следовательно, в процессе доказывания в судопроизводстве, экспертом устанавливается искомая причина, к соответствующему ей следствию.

Процесс познания природе призван быть объективным, материалистическим, но и в то же время связан с большим количеством факторов, со своими непосредственными задачами и целями.

Следствием экспертного судебного заключения является познавательная деятельность, осуществляемая экспертом на основе внешних объективных и внутренних, субъективных факторов [6, с.81].

Важная роль в познавательной деятельности судебного эксперта отведена наблюдению, непосредственной основой которого является восприятие.

Психологическое содержание наблюдения определяется как длительное целенаправленное восприятие какого-либо объекта, проводимое по определенному плану с последующим анализом и обобщением полученных данных выбранной методики исследования. Поставленная перед субъектным экспертом мыслительная задача определённого типа, требующая соответствующего решения, достигается познанием на основе внешних, объективных и внутренних, субъектных факторов, анализ которых, в итоге формирует убеждение в правильности достигнутого решения 


\begin{tabular}{llllll} 
& ISRA (India) $=\mathbf{3 . 1 1 7}$ & SIS (USA) & $=\mathbf{0 . 9 1 2}$ & ICV (Poland) & $=\mathbf{6 . 6 3 0}$ \\
Impact Factor: & ISI (Dubai, UAE) $=\mathbf{0 . 8 2 9}$ & PUHL (Russia) $=\mathbf{0 . 1 5 6}$ & PIF (India) & $=\mathbf{1 . 9 4 0}$ \\
& GIF (Australia) $=\mathbf{0 . 5 6 4}$ & ESJI (KZ) & $=\mathbf{8 . 7 1 6}$ & IBI (India) & $=\mathbf{4 . 2 6 0}$ \\
& JIF & $\mathbf{1 . 5 0 0}$ & SJIF (Morocco) $=\mathbf{5 . 6 6 7}$ & OAJI (USA) & $\mathbf{0 . 3 5 0}$ \\
\hline
\end{tabular}

поставленной задачи. Судебная экспертная деятельность основана на практических методиках научного направления, применяемых в доказывании тех или иных фактов, событий, поэтому познавательная деятельность судебного эксперта носит прикладной характер. Правильно подобранная логическая форма, как способ связи составных частей мыслительного процесса, ее анализ концептуальных образований, это понятий, суждений обуславливает доказательную ценность выводов эксперта, хотя заключение, являясь одним из доказательств, не обладает приоритетом в сравнении с другими, предоставляемыми участниками процесса, согласно статей 55,9,60,67 ГПК РФ, как и статей 74,88 УПК РФ [7, с. 175].

Отводя важную роль психологической составляющей субъектного образа судебной экспертизы, образуется понимание природы и процесса формирования внутреннего убеждения эксперта, которое обуславливает творческое мышление с логическими операциями, необходимыми в данных видах исследований.

\section{Conclusion}

Отличительная черта экспертного заключения, в сравнении с другими видами доказательств, обуславливается субъектностью выводов, основанных на специальных познаниях, основанных на научных методах, имеющих доказательственное значение. Анализируя и сопоставляя экспертное заключение с другими доказательствами по делу, происходит его оценка судом или следователем, на основании логичности, последовательности ясности изложения с полным обоснованием выводов по поставленным вопросам.

\section{References:}

1. Aver'yanova, T. V. (2017). Kurs obshchej teorii sudeb-noj ekspertizy. (p.407). Moscow: Norma.

2. Arsen'ev, V. D. (1964). Voprosy obshchej teorii su-debnyh dokazatel'stv. (p.179). Moscow: Yurid. Literatura.

3. Belkin, P. C. (1964). Sobiranie, issledovanie $i$ ocenka dokazatel'stv. (p.295). Moscow: Yurid. Literatura.

4. Gal'perin, P. Y. (2000). Vvedenie v psihologiyu. (p.336). Moscow: Universitet.

5. Gegel' (1990). Filosofiya prava. (p.526). Moscow: JT.

6. Dulov, A. B. (1975). Sudebnaya psihologiya. (p.464). Minsk: Vyshejsh. Shkola.

7. (2003). Kommentarij k Federal'nomu zakonu «O gosudarstvennoj sudebno-ekspertnoj deyatel'nosti v Rossijskoj Federacii» ot 31 maya 2001 g. I Pod obshch. red. Kashepova V.P. (Eds.). (p.240). Moscow: Yusticin-form.
8. Leont'ev, A. N. (1975). Deyatel'nost'. Soznanie. Lich-nost'. (p.304). Moscow: Politizdat.

9. Majlis, N. P. (2006). Moya professiya sudebnyj ekspert. (p.168). Moscow: SHCHit-M.

10. Mishchik, S. A. (2014). Pedagogometrika $i$ matematiche-skoe modelirovanie uchebnoj deyatel'nosti. Materialy Mezhdunarodnoj nauchnoj konfe-rencii «Modern mathematics in science» - 30.06.2014. International Academy of Theoretical \&Applied Science, №6 (14), Caracas, Venezuela, pp.54 - 56.

11. Obozov, H. H. (1990). Psihologiya mezhlichnostnyh otnoshenij. (p.191). Kiev.: Nauka.

12. Reshetova, Z. A. (2013). K voprosu o mekhanizmah usvo-eniya i razvitiya. Nacional'nyj psihologiche-skij zhurnal, № 1(9), pp. 25-32. 